\title{
Transformative outcomes: assessing and reorienting experimentation with transformative innovation policy
}

\author{
Bipashyee Ghosh ${ }^{1}{ }^{1}$, Paula Kivimaa ${ }^{1,2}$, Matias Ramirez ${ }^{1}$, Johan Schot ${ }^{3, *}$ and Jonas Torrens ${ }^{4}$
}

${ }^{1}$ Science Policy Research Unit (SPRU), University of Sussex, Jubilee Building, Falmer, Brighton BN1 9SL, UK, ${ }^{2}$ Climate Change Programme, Finnish Environment Institute SYKE, Latokartanonkaari 11, Helsinki 00790, Finland, ${ }^{3}$ Utrecht University Centre for Global Challenges, Janskerkhof 2-3A, 3512 BK Utrecht, The Netherlands and ${ }^{4}$ Copernicus Institute of Sustainable Development, Vening Meinesz Building A, Princetonlaan 8a, Utrecht 3508TC, Netherlands

*Corresponding author. E-mail: j.w.schot@uu.nl

\begin{abstract}
The impending climate emergency, the Paris agreement and Sustainable Development Goals demand significant transformations in economies and societies. Science funders, innovation agencies, and scholars have explored new rationales and processes for policymaking, such as transformative innovation policy (TIP). Here, we address the question of how to orient the efforts of science, technology, and innovation policy actors to enable transformations. We build on sustainability transitions research and a 4-year co-creation journey of the TIP Consortium to present twelve transformative outcomes that can guide public policy agencies in evaluating and reformulating their projects, programmes, and policies. We illustrate the transformative outcomes in two empirical cases: transitions towards mobility-as-a-service in the Finnish transport system and the emergence of speciality coffee in Colombia. We argue that the twelve transformative outcomes can guide public policy agents to fundamentally transform their ways of thinking and operation in advancing transformative change.
\end{abstract}

Key words: innovation policy; sustainability transitions; transformation; transformative outcomes; experimentation; policy engagements.

\section{Introduction}

Policymakers working in science, technology, and innovation (STI) are facing pressures not just to focus on economic growth and competitiveness but to address contemporary challenges such as global environmental change, growing inequality, and now a socio-economic health crisis in the aftermath of Covid-19. This is most evident in governmental responses to recent global policy agendas, such as the Sustainable Development Goals (SDGs), the Paris Climate Agreement, the European Union Green Deal, and the 2020 World Economic Forum agenda on 'Fixing inequality'. In each case, reorienting the efforts of public science funders and innovation policy professionals is positioned as an important ingredient for initiating societal change in more sustainable directions. Various studies note a mismatch between traditional innovation policy and the actions needed to address environmental and social sustainability (Edler and Fagerberg 2017; Boon and Edler 2018; Borrás and Laatsit 2019).

A new wave of STI policies labelled as transformative innovation policy (TIP) aims to address this mismatch (Steward 2012; Weber and Rohracher 2012; Schot and Steinmueller 2018; Diercks et al. 2019; Grillitsch et al. 2019). Weber and Rohracher (2012: 1041) argue that this new generation of policies should address 'transformational system failures' that are 'preventing processes of transformative change from occurring in a socially and politically desirable way'. They identified four key failures that hinder transformative change: lack of directionality, wrongly directed demand articulation, lack of policy coordination, and reflexivity failure. To overcome these failures and confront the mismatch among ambitions, approaches, and achievements, Schot and Steinmueller (2018) and Diercks et al. (2019) argued that TIP should be focussed on socio-technical system change and be approached experimentally, building on sustainability transitions research, in particular, using concepts such as niche, regime, and socio-technical landscape as a basis (Rip and Kemp 1998; Grin et al. 2010; Geels 2002). While the idea and narrative of TIP is established, it remains unclear how to implement such a policy.

Here, we therefore address the question of how to orient the efforts of STI agencies to enable transformations and address societal challenges. Our brief answer is by focussing on transformative outcomes. Rather than foregrounding the transformational failures, the focus is on enabling and navigating ongoing transformation dynamics. For that, we introduce twelve transformative outcomes (TOs), which encompass a new framework across three macro-processes that can guide the interventions and evaluation of TIP towards more transformative aims. We further introduce the notion of experimental policy engagements (EPEs) as a way to characterise these interventions. These two concepts taken together can provide a basis for the implementation of TIP by STI agencies, offering an entry point for more reflexive and effective engagements with transformative change. ${ }^{1}$

This paper distils the experience gathered in the Transformative Innovation Policy Consortium (TIPC), a 5-year

(c) The Author(s) 2021. Published by Oxford University Press.

This is an Open Access article distributed under the terms of the Creative Commons Attribution-NonCommercial License (https:/creativecommons.org/ licenses/by-nc/4.0/), which permits non-commercial re-use, distribution, and reproduction in any medium, provided the original work is properly cited. For commercial re-use, please contact journals.permissions@oup.com 
trans-disciplinary research and action programme ${ }^{2}$ where STI policymakers from several countries from the Global North and South worked with a research team to articulate the concept of TIP, explore how to use it in practice, and build capabilities around it. TIPC positions itself as a learning platform for co-creating a new generation of approaches that experiment with advancing socio-technical system change and identify new ways of evaluating such experiments. We draw from a series of activities aimed at bridging academic and policy knowledge in ways that support intentional and reflexive policy praxis and respond directly to a demand from TIPC members for approaches to conduct and evaluate their transformation efforts.

We structure this effort as follows. In Section 2, we introduce our co-creation journey and how we have combined the co-creation process with literature review and two case studies from the TIPC programme to refine the application of our approach. We also introduce the EPE concept as a rationale for our focus on TOs. Section 3 articulates and substantiates the twelve TOs, grounded in a literature review. Section 4 presents the two explorative case studies, concerning mobility-as-a-service (MaaS) in Finland and specialty coffee in Colombia, reinterpreted through the TOs framework. In Section 5, we draw lessons on how to apply a TOs framework for TIP. In Section 6 we provide conclusions.

\section{Research approach: a co-creative journey with policymakers}

The TOs presented here resulted from a co-creative ${ }^{3}$ journey between several STI agencies ${ }^{4}$ and researchers, in the TIPC. This journey was rooted in shared but context-specific efforts of national innovation agencies and research councils to address societal and ecological challenges, as expressed in the 2009 Lund Declaration and in 2015 UN Agenda 2030 SDGs. This was a trans-disciplinary process (Mauser et al. 2013; Pohl et al. 2017): the research team worked with policymakers in framing the problem, to identify and define the research question, engaged with them in empirical research, and involved them in drawing conclusions. Four steps of that journey are relevant here.

First, in a pilot phase (2016-2017) policymakers and researchers explored how TIP was understood and what processes may bring it about in distinct contexts of application, to better frame the activities of the consortium. The team conducted country reviews and pilot cases to elicit indications of transformations and to inductively refine the understanding of TIP. The results confirmed the emergence and proliferation of policies and programmes aimed at inducing transformations in the Global North and South and highlighted the important role for STI policies in addressing deep systemic problems. The combined growing popularity of mission-oriented and transformation-oriented rationales among the members is noted (see Mazzucato 2018; Diercks et al. 2019; Schot and Steinmueller 2019). However, members reported difficulties in integrating these rationales into the practices and instruments at their disposal. The key problem, identified by the policymakers, was practical and conceptual difficulties about how to do and evaluate TIP or mission-oriented policies. This joint conclusion motivated the focus on developing a methodology for experimentation and evaluation in the subsequent 5 -year TIPC programme.
Second, during 2018-2019, TIPC conducted an empirical study of different modes of experimentation to conceptualise how attempts to experiment with new policies and approaches contributed to transformation at large, beyond the novelty creation and ad hoc experiments with little (policy) impact (Turnheim et al. 2018; Schot et al. 2019). This resulted in developing the notion of EPEs as the diverse ways in which (STI) policy makers engage with processes of societal experimentation for sustainable transformation: initiating, supporting or mobilising, and evaluating such initiatives for informing decision-making, enabling processes of social learning, developing alternative pathways and enacting desirable futures.'

EPEs differ from transition theory view of experimentation centred on creating novelty and building niches (Rip and Kemp 1998; Smith and Raven 2012; Sengers et al. 2016). EPEs highlight how different forms of experimentation can also play a role in the expansion of niches and destabilisation of dominant practices or regimes (see Torrens et al. 2018). Moreover, experiments are not seen as isolated projects but as interventions in larger multi-actor transformation processes. Accordingly, TIPC members expressed a need for a methodology to help them improve existing interventions. This need was translated into the questions 'how STI projects, programmes and policies, redefined as EPEs, can be made more transformative, and how STI agents can know progress is made in terms of transformation'.

Third (largely in parallel to Step 2), the authors co-created with TIPC members the TOs presented here. Based on a literature review of sustainability transitions, the authors initially drafted the list of TOs in coordination with other TIPC researchers. To refine that list, the authors presented, discussed, and used the TOs in several workshops with TIPC members in 2019 and 2020, such as the TIPC Learning journey (June 2019), TIPC training week in South Africa (September 2019), TIPC engagement week in Spain (November 2019) and a VINNOVA workshop in Sweden (February 2020). In total, these activities involved over 200 STI policymakers and researchers from a range of contexts. With hands-on exercises, we came to understand how TOs could be used to improve the design of EPEs and the reformulation and evaluation of existing policy approaches (in connection to TIPC activities on formative evaluation (see Molas-Gallart et al. 2020)). The co-creative process allowed TIPC members to develop a shared understanding about the approach and illustrated its application in different contexts. The result of that process is the refined list of the twelve TOs (in Section 3).

Throughout this journey, our approach is best described as abductive inference, which involves the interpretation, re-description, and re-contextualisation of individual phenomena within a conceptual framework, that leads to understanding that phenomena in a new way and a better appreciation and refinement of theory (Danermark et al. 2002). For that, we constantly switch between theory and practice, with the multiple events mentioned above allowing for testing iterations. Preliminary versions of this paper were used as an input in those events. In each stage, we collated feedback from TIPC members and refined the TOs description and explanation.

Fourth, we used a more classical case study approach to explore the TOs relevance by revisiting and updating two case studies conducted during the TIPC pilot (2016-2017). 
This analysis was done without consultation with the TIPC members. The selected cases are the emergence of MaaS in Finland and of specialty coffee production in Colombia. Four reasons informed this selection. First, the cases represented two drastically dissimilar contexts, which helped establish whether the preliminary list of TOs would be relevant beyond the European context. Second, both cases showed signs of a partial success in enabling a transformation but in different degrees of maturity. Third, there was a stark contrast in how proactive policymakers were in their engagements. In Colombia, there was little engagement that happened late in the process. In Finland, policymakers' engagement was intense and from an early phase. Finally, in both cases, the TIPC team had collected extensive data, or continued to collect data (Finnish case), and lead investigators could join our study. The original data collection included workshops, interviews, and secondary document analysis (see Arond et al. 2017; Kanger and Kivimaa 2017; Kivimaa and Rogge 2020). We summarised the main developments and policy interventions in a new narrative, including the coding for different TOs.

\section{Transformative outcomes}

In sustainability transitions theory, change is an evolutionary process characterised by a myriad of interacting variables that are co-evolving through time and space (Elzen et al. 2004; Grin et al. 2010). No actor is in the position to control the process. Yet, many actors influence and navigate sustainability transitions (Voss et al. 2006). In elaborating the TOs, we focus on how research councils, science and technology ministries, and innovation agencies can improve their actions through a more systemic and continuous governance approach building on sustainability transitions thinking. This can be done by conceiving their projects, programmes, and policies as EPEs for achieving specific TOs. We argue that if STI policy actors work towards achieving these TOs, they may overcome the transformational failures by inducing directionality, reflexive thinking, improving policy coordination, and demand articulation (Weber and Rohracher 2012).

A key question is then, what are these TOs that actors may target to fulfil? Based on a review of the sustainability transitions literature and our interactions with policymakers in a TIPC setting (see Section 2), we propose twelve TOs across three macro-processes that underpin socio-technical change through multi-level interaction: (1) building and nurturing niches; (2) expanding and mainstreaming niches; and (3) unlocking and opening up of regimes. We propose four outcomes in each of these macro-processes (adding up to twelve) as a new theoretical framework operationalisable in formative evaluation of transformation innovation policy (Molas-Gallart et al. 2020). Note that in our framework, the notion of 'outcome' refers to a semi-abstract goal to achieve, for example, a better network but also a process of networking that will develop over time. TOs are not prescriptive tasks and can be stretched for transformation purposes (see Table 1 for a full overview of twelve outcomes and example EPEs).

Before explaining the TOs, it is crucial to explain four theoretical underpinnings that constitute the philosophy beyond TOs. First, TOs are conceptualised as processes or interventions that lead to deeper changes in sets of rules that guide actors (individuals but also groups and organisations) in their behaviour. ${ }^{5}$ Actors can use these rules because of fear of sanctions (following from regulations), their cognitive beliefs, and/or their values (Geels et al. 2016; Ghosh and Schot 2019). In socio-technical systems, these rules are shared among regime actors, stabilised and manifested across the different system dimensions such as science and technology (artefacts and infrastructures), market structure (including user preferences), industry structure, policy and politics, and symbolic meanings that make the system culturally attractive. Therefore, sustainability transitions are not only about changing systems, but also about changing the underlying rules that actors use to build, optimise, and maintain the system.

Second, the macro-processes that encompass TOs emerge from a specific theory of change; one where socio-technical change occurs through dynamic and complex interactions between niches, regimes, and the landscape, as conceptualised in the Multi-level Perspective (Rip and Kemp 1998; Geels et al. 2016). This theory of change embraces the idea that transformations of dominant and unsustainable socio-technical regimes (stable rule-set) follow distinct pathways depending on the emergence and maturity of alternative socio-technical systems in niche spaces and the influence of trends and shocks (the climate crisis, increasing inequality, pandemics such as Covid-19, and digitalisation) called the socio-technical landscape in 'hollowing out' the regime and offering the context for alternatives to stabilise (Smith et al. 2005; Schot and Geels 2007).

Third, how TOs are enacted is a deeply political process, riddled with choices and conflicts between multiple actors with incongruent interests. This prompts the question: which actors to involve. We propose to think about this in three ways. First, given the multiple system dimensions, transformation processes should include actor groups corresponding to particular dimensions; this means inclusion of users, citizens, industry, government, knowledge institutions, and actors of the cultural dimension such as artists and media. Second, transformations need deliberations between diverse sets of regime and niche actors; regime actors are those people and organisations who believe and value the regime rules, while niche actors have alternative preferences, playing a crucial role in experimenting and enabling change as visionaries who are less constrained by the regime rules (Holscher et al. 2019). While both regime and niche actors are important, for a sustainability transition to happen regime actors should not dominate. Between the dichotomy of niche and regime actors, there are also 'intermediary' actors who play critical roles in bridging the differences between conflicting interest groups and 'orchestrate' a way forward (Kivimaa et al. 2019; Sovacool et al. 2020b) Third, sustainability transformations involve addressing systemic inequality, injustice, and marginalisation of actor groups, including unequal distribution of benefits. Sustainability transitions, particularly from a Global South perspective, should empower people and organisations who will be most adversely impacted by the current practices (Swilling 2019; Ghosh and Sharmeen 2021).

Fourth, TOs unfold not only over time, but also spatially. The implications of spatial sensitivity of the framework are twofold. The system configuration, rules, actornetworks, and the theory of change have to be situated in place-based conditions that have a crucial role in enabling or disabling transformational processes (Hansen and Coenen 2015). Hence, TOs should be applied to address contextspecific institutional conditions and demonstrate the role 
Table 1. How do EPEs contribute to achieving TOs.

\begin{tabular}{ll}
\hline Macro-process & TO \\
\hline $\begin{array}{l}\text { 1. Building and } \\
\text { nurturing niches }\end{array}$ & 1.1. Shielding
\end{tabular}

1.2. Learning

1.3. Networking

1.4. Navigating expectations
EPEs contribution

Offering protection for niche experiments and normalising these protection measures.

Broadening: identifying, testing, and developing strategies to protect niches covering multiple system dimensions, encompassing a wide range of experiments and more diverse alternatives.

Examples: providing subsidies for innovation projects (STI dimension), parking benefits to electric vehicles (market dimension), or media campaigns to promote organic food (cultural dimension).

Deepening: align various shielding measures, across system dimensions and across geographies.

Examples: providing a permanent VAT exemption for organic food, integrating organic food consumption into standards for food provision in schools, and making specific (parts of) cities only accessible for electric vehicles

Induce first- and second-order learning in niche experiments. First-order learning focuses on improving what actors are doing while second-order learning questions frames and assumptions of structures and activities.

Broadening: including more dimensions of the system in first- and second-order learning processes and incorporating different forms of knowledge (e.g. beyond technical knowledge from a single discipline), involving multiple actors (diversity and trust) and aspects of sustainability.

Examples: not only focus on how to develop solar technology but also address opportunities and barriers for viable business models, and consumer behaviour integrating various knowledge aspects and actors in the learning process.

Deepening: creating opportunities for challenging assumptions (about preferred solutions, problem definitions, and whether and how they contribute to sustainability).

Examples: performing a study with multiple actors about the question whether and how biofuels contribute to the SDGs; and organising a workshop with diversity of actors about the question whether electric vehicles are just a solution for the rich, and whether and how they will reduce car mobility substantially

Create high-quality opportunities for collaboration between actors, strengthening their networks.

Broadening: convening joint activities with enough flexibility around which multiple actors can congregate and mobilise, and acknowledging diverse beliefs, values, and concerns.

Examples: including a diversity of patients, civil society actors, food shops, fitness centres, and schools next to healthcare professionals, policymakers, and insurance companies in an experiment with a new way of local healthcare provision that integrates healthcare with life style.

Deepening: enhancing the mobilising power, mutual trust, and coordination among the actors involved in niches ensuring the stability of actors-networks over a longer period.

Examples: establishing intermediary niche actors that build platforms for more permanent interaction among various actors

Create spaces for articulating expectations around societal challenges and appraising these expectations to enhance their credibility (among niche actors), quality (providing more evidence), and stability (expectations are not questioned anymore).

Broadening: allowing a diversity of actors to voice their expectations around landscape challenges, regime ability to respond, and promise of niches to provide solutions. Requires accepting and making explicit tensions and conflicts of interest among expectations.

Examples: organising futuring processes that articulate several expectations about the future of water management in a specific region addressing conflicting demands by farmers, ship owners, consumers, and nature conservation, and allows for deliberating these futures.

Deepening: developing credible expectations by aligning landscape, regime, and niche expectations of niche and regime actors and supporting this alignment with concrete evidence.

Examples: by organising a transition arena where actors have to create a shared vision and proposals for a set of experiments for new water management practices they will collectively develop and fund 
Table 1. (Continued)

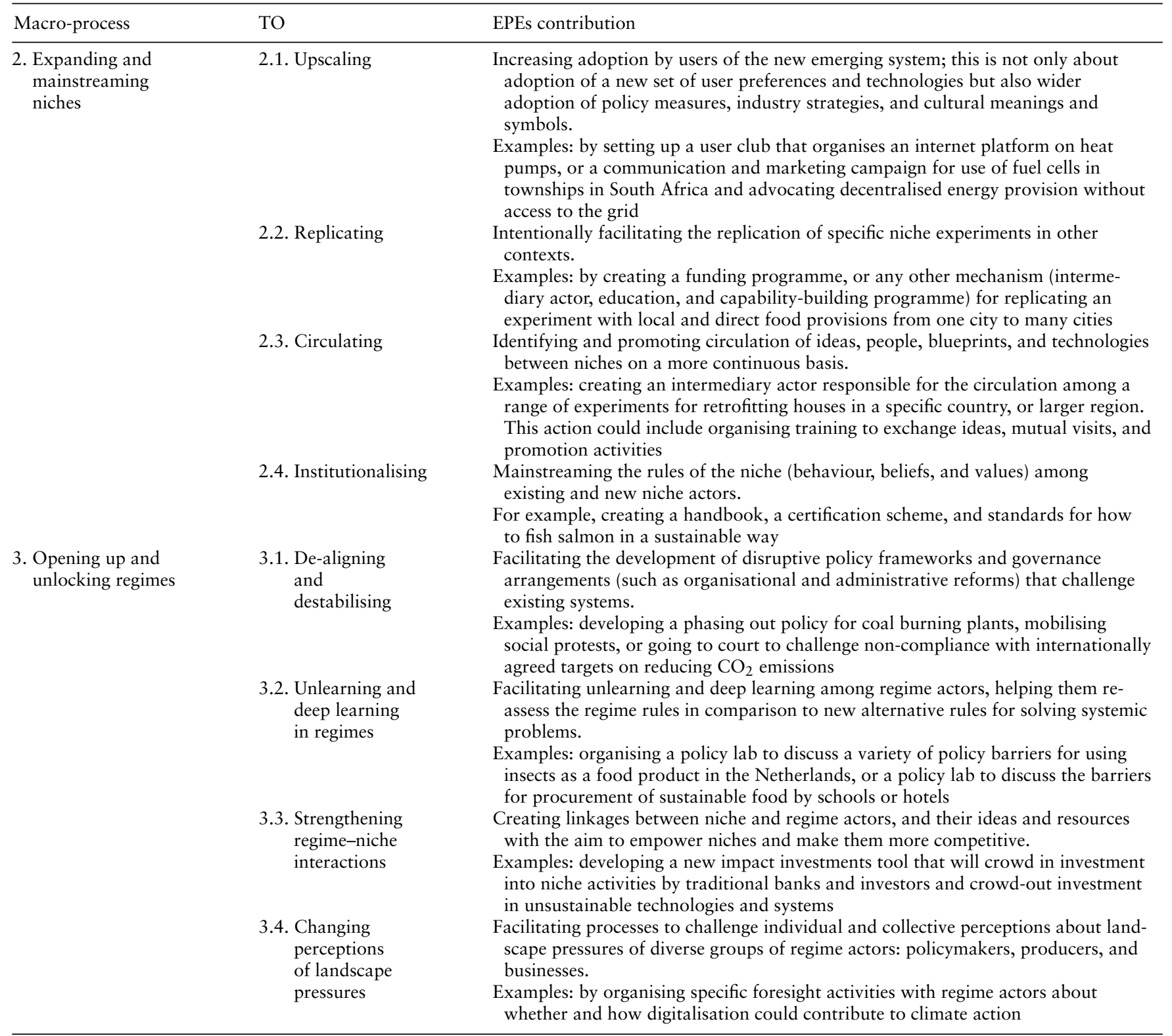

of transformative innovation in many socio-spatial contexts (Dignum et al. 2020; Binz et al. 2020). Moreover, the spatial dimension varies across the TOs. While TOs associated with building niches can be tracked in specific geographical locations, the ones associated with expanding and mainstreaming are rarely confined to local contexts, but encompass activities, actors, and resources scattered over distinct scales and geographies. Expansion and mainstreaming need supportive networks that span to regional, national, and international settings and mobilise experiences from several locations to enrich or justify local experiments (Wieczorek et al. 2015; Avelino et al. 2020). Multi-scalar work implies connecting local niches and regimes to global ones (Bauer and Fuenfschilling 2019).

Next, we describe each TO and exemplify its applicability, providing sufficient granularity for evaluative and reflexive processes as developed in TIPC. In our experience, while implementing the TOs, there is no right or wrong sequence.
Neither is it necessary to make a qualitative judgement of whether one is more transformative than the other. On the contrary, innovation policymakers should work on a selected portfolio of TOs to accelerate ongoing transformation processes. Which TOs to target, in what sequence, and how many to achieve through an EPE are contextual and contingent on different capacities and constraints.

\subsection{Building and nurturing niches}

Niches are valuable for transformations because they provide spaces for building alternative practices from which new rules and systems can emerge. They are seedbeds, harbours, and battlegrounds for transformation (Torrens et al. 2019). The conceptualisation of this process is based on strategic niche management theory (Rip and Kemp 1998; Raven et al. 2010). Within the process of building and nurturing niches, four TOs are identified: (1) shielding, (2) learning, (3) networking, and 
(4) navigating expectations. For each outcome we introduce a distinction between broadening and deepening. The former relates to expanding the scope, while the latter focuses on improving the quality and directionality of the process (Schot and Steinmueller 2018).

\subsubsection{Shielding}

Shielding means creating conditions for niche innovations to thrive by fencing off incumbent interests. Shielding mechanisms may include direct support for radical niche innovations through R\&D or deployment subsidies, preferential tax treatment, public or collective purchasing, voluntary agreements, regulation, and/or information campaigns (Raven et al. 2010). This is active shielding (Smith et al. 2014) to 'protect the niche' from being exposed to economic, political, institutional, and exogenous pressures. Specific pre-existing geographical and spatial conditions such as 'remote locations', culture of resistance, network-building and activism may provide passive shielding to niches (Smith et al. 2014; Boon et al. 2014). Active and passive shielding can coexist, but it is desirable that niches continue to receive passive shielding even after active cover is removed, and that shielding becomes a routinised niche actor behaviour.

We propose that deliberate interventions by policymakers and other actors 'broaden shielding' by increasing the diversity of active strategies to protect multiple alternative niches in different system dimensions (new policy, business model, new scientific knowledge, user preferences, and new symbolic meaning of the alternative). We further propose policymakers and other actors to 'deepen shielding' by strengthening the various actor strategies and align them better across the system dimensions and spatial scales. EPEs for how to broaden and deepen shielding of the niche in and beyond a specific context is important for facilitating transformative change at local, regional, or national levels.

\subsubsection{Learning}

Learning is a cognitive process of knowing, understanding, and reflecting. Such processes are the core to niche building and nurturing as radical innovation can only happen through continuous learning in strategic locations that shielding offers (Schot and Geels 2008; Raven et al. 2010; Naber et al. 2017). According to strategic niche management, one can distinguish between first-order and second-order learning (van de Kerkhof and Wieczorek 2005; Smith and Raven 2012; Pellicer-Sifres et al. 2018). While first-order (single-loop) learning is about knowledge accumulation for determining solutions to specific problems in a specific context, secondorder (double-loop) learning is about thinking through the process of approaching the problem in itself. It is 'higher order learning', often associated with 'learning-by-doing' through which niche actors continuously reflect, adapt, and challenge other actors' assumptions and perceptions of 'problem solving, problem definition, dominant interpretative frame and worldview' (Sengers et al. 2019: 157; Van Mierlo and Beers, 2020). Both first- and second-order learning are important for transformation. However, second-order learning is more important and is deemed more transformative, because it challenges the underlying regime rules (Mezirow 2000; Loorbach et al. 2011; van Poeck et al. 2020).

As a TO, policy actors and other actors involved in niches can design interventions for 'broadening of learning' by enabling learning in more than one system dimension across multiple systemic actors (e.g. engineers looking beyond technical knowledge) and ensuring that also second-order learning is happening. This means continuous reflection and challenging assumptions/biases to build a long-term, robust, and collective problem-solving capacity for the whole system (van Poeck et al. 2020). Policy actors can design specific interventions for 'deepening of learning' by training multiple actors to stretch their thinking beyond existing routines and norms and acquire a deeper, holistic, and context-specific understanding of the sustainability problems faced by the socio-technical system they are embedded in (Raven et al. 2019). Deepening learning is an important TO as it enhances reflexivity, mutual trust between actors, and collective retention of new rules, thereby facilitating easier translation of the first-order learning from niche into more generalisable, stabilised rules. This is a step towards setting transformative directionality through selective retention of rules in the formation of new regimes (Sol et al. 2017; Safarzyńska and van den Bergh 2013; Turnheim et al. 2018; Borghei and Magnusson 2018; Van Mierlo and Beers, 2020). For broad and deep learning to occur, the type and quality of actor-networks is a key factor.

\subsubsection{Networking}

Since transition is a multi-actor process, this process is bound to fail if these actors do not interact, share ideas, exchange resources, and work together to complement and enhance each other's skills, knowledge, and capabilities (Avelino et al. 2020). An explicit strategy for enabling networking between diverse niche actors is imperative to niche-building processes.

Networking as a TO can be achieved through broadening and deepening of social networks emerging and existing around niches. As niches are built, policy actors can contribute to 'broadening of networks' by creating new networks composed of niche and regime actors from diverse backgrounds, knowledge, and skills (Smith and Raven 2012). This effort should include actors from various system dimensions (e.g. government, business, civil society, and scientific institutions) and different sections of the society (economic elites and marginal groups). Such broadening raises the transformative potential of niches through engaging with several perspectives that reduce the risk of social exclusion, discrimination, and lock-in to a single transition trajectory. However, solely broadening networks might lead niche actors conforming to the dominant views of the regime. Hence, an effort into deepening of networks is important to mitigate this conformity. 'Deepening of networks' can be achieved through building mutual trust and commitments within the newly emerging networks (Schot and Geels 2008; Naber et al. 2017; Sol et al. 2018). Such an effort might require specialist interventions of a new set of actors called 'niche intermediaries' who are skilled at facilitating mutual connections, creating a shared narrative between actors, and consolidating the niche (Kivimaa et al. 2019). They bring together multiple actors' experiments and strengthen the 'common voice' (Smith and Raven 2012). The goal of deepening is therefore to improve the quality of actor-networks so that they can 'stretch and transform' the regime. Networking, through broadening and deepening, is a TO that contributes to shaping new expectation dynamics within niches.

\subsubsection{Navigating expectations}

Niche actors' collective expectations about future trends and shocks at the landscape level, the ability of regimes to respond to exogenous and endogenous pressures, and the potential of 
innovations to address problems in the regime are a crucial determining factor of whether and how niches are built and nurtured (Truffer et al. 2008; Smith and Raven 2012). Expectation dynamics can be volatile and develop with hype and disappointment cycles (Verbong et al. 2008; Konrad et al. 2012). They may vary across niche and regime actors and across socio-political and cultural contexts (Brown and Michael 2003; Coenen et al. 2010; Budde et al. 2012). As a result, niche actors are required to 'navigate' a 'sea of expectations' and the ambiguity it generates, before they may find some convergence into shared visions, eventually guiding niche development (Borup et al. 2006; Raven et al. 2010; van Lente 2012). Therefore, an explicit effort in navigating the diverse expectations arising from broadening networks to arrive at shared and inclusive visions of the future is what makes the system transformative. Such navigation, supported by (but not limited to) reflexive learning, allows explicit negotiation between contested and contradictory visions (instead of hiding them) leading to more robust and widely shared expectations about the future of socio-technical systems (Konrad 2006).

To mobilise the navigation of expectations as a TO, niche policy actors should first put efforts in broadening the pallet of expectations, by actively seeking to accumulate visions from multiple actors, which involves acknowledging tensions and conflicts of interests in several articulated (and unarticulated) expectations (Borup et al. 2006; Jørgensen 2012; Delina and Janetos 2018). Broadening also refers to being open to diverse expectations about many issues such as landscape trends, the quality of regimes, and niche performance (Truffer et al. 2008; Budde and Konrad 2019). Broadening expectations is an accommodation process. A complementary process, 'deepening expectation dynamics', is to find alignments between diverse articulated expectations, which sets the directionalities of future transitions (Truffer et al. 2008; Budde and Konrad 2019). Deepening also involves evaluating the quality, stability, and credibility of expectations through mapping evidence underlying each expectation. This is part of the negotiation process, which can help navigating hype cycles and contestations and open up possibilities of multiple radically different futures sensitive to local contexts.

\subsection{Expanding and mainstreaming niches}

For transitions to happen, niches need to expand in size and scale. The expansion process implies that the rules and practices emerging in the niche are 'mainstreaming' (Gibbs and O'Neill 2015). Mainstreaming is a level of acceptance and credibility that assists in the take-up or adaptation in contexts outside of the niche's immediate origin. Four TOs can be discerned from the literature on niche acceleration and embedding (Naber et al. 2017; Turnheim et al. 2018; Mellen 2018): (1) upscaling, (2) replicating, (3) circulating, and (4) institutionalising. The latter three contribute to upscaling, while they are distinct processes that can be shaped by EPEs separately from focussing on upscaling as such. Fig. 1 illustrates these outcomes with 'time' in the horizontal axis and 'stability of rules' in the vertical axis.

\subsubsection{Upscaling}

Upscaling as a TO can be associated with the adoption of the niche innovation by more users (Turnheim et al. 2018). The adoption is not of a technology, process, or product, but of the entire system of the 'niche' and embedded rules. Drawing from the notion of 'system diffusion' (Geels and Johnson 2018), upscaling is about societal embedding of niche

\section{TRANSFORMATIVE OUTCOMES FOR EXPANDING \& MAINSTREAMING NICHES}

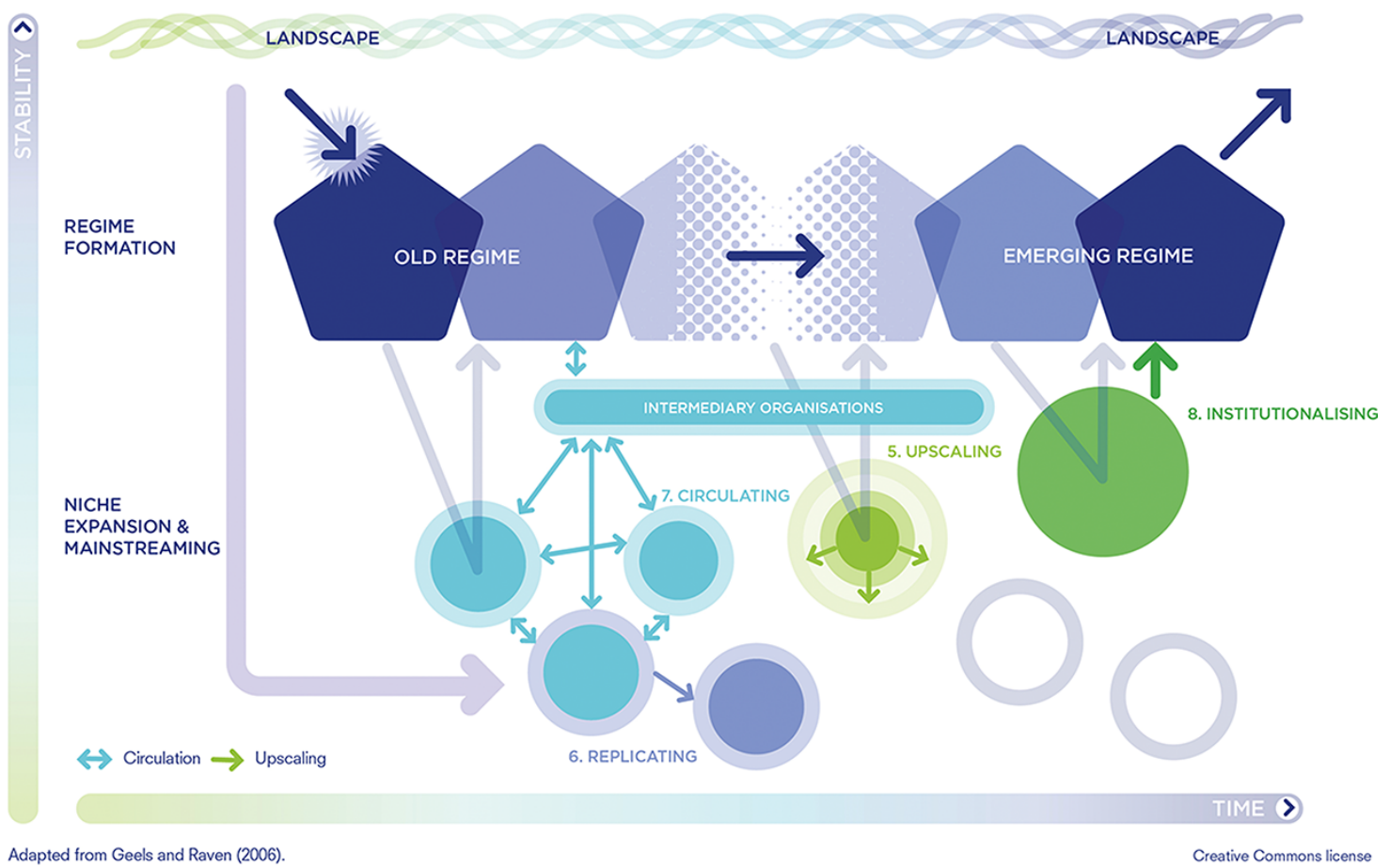

Figure 1. TOs in niche expansion and mainstreaming (adapted from Naber et al. 2017). 
innovations facilitated through developing policy measures, industry strategies, and cultural meanings for more user adoption (Jolly et al. 2012; Seyfang et al. 2014). In a recent study on solar development in China, Yang et al. (2020) argue that, when 16 per cent of the potential users adopt a niche innovation, system diffusion accelerates; new users adopt not just the technology (solar photovoltaic cells and panels) but also accept the new rules embedded in the technology as a (future) mainstream option. In our framework, upscaling is geographically bounded by the size and location of the market and embeddedness of users in the local-cultural context, even though actors and resources from elsewhere may also contribute to this expansion.

\subsubsection{Replicating}

Replicating refers to the geographical expansion of the niche, by recreating similar niche spaces in new socio-spatial and cultural contexts (Bos et al. 2013; Turnheim et al. 2018). An expected output of replicating is geographically disconnected yet similar niches emerging in their own local contexts with their own shielding and nurturing strategies. An example is the replication of bike sharing niches in different cities around the world with different strategies to protect the niche (van Waes et al. 2020).

Replication is heavily dependent on socio-institutional, political, and cultural conditions (Coenen and Truffer 2012; Hansen and Coenen 2015; Raven et al. 2012). As a TO, replication needs to be specifically anchored to a context in spite of the accumulated learning and knowledge flow from other contexts (Carvalho and Lazzerini 2018). This process involves de-contextualisation from their source and consequent recontextualisation in the new context through consolidation and packages of learning for spatial transfer, followed by unpackaging, reinterpretation, and embedding in the new context (Seyfang et al. 2014: 23). The success, failure, and transformative potential of a replicated niche depend on these processes and local niche actors' awareness and estimation of context (Feola and Nunes 2014).

Certain intermediary actors, such as international organisations, can help replication as they may have capacities to work in and knowledge about multiple local contexts (Hanen and Nygaard 2013). Yet, examples of global intermediaries skipping the de-contextualisation and re-contextualisation process to imitate the same niche in multiple locations also exist (Seyfang et al. 2014). Successful replication of niches may also be facilitated through empowering local actors to try out successful niches from elsewhere if they have shared problems, future visions, and perceptions of landscape pressures, such as the need to shift to a low-carbon society (Seyfang and Haxeltine 2012).

\subsubsection{Circulating}

Circulating as a TO is distinguishable from upscaling and replicating by its nature of spatiality and specific actors' contributions in enabling circulation. Circulating elements of a niche (e.g. ideas, people, values, products, texts, and learning) elsewhere can be transformative if it enables niche building and expansions in multiple places simultaneously. It is beneficial as multiple niches from different spatial and cultural contexts connect, leading to the overall expansion of the global niche (Geels and Deuten 2006; Gosens et al. 2020).
Circulation of a niche can happen through trans-local interactions between geographically dispersed, yet globally (virtually) or nationally connected, user communities who serve as a 'centralised knowledge archive' and help in recontextualising systems to diverse local contexts (Meelen et al. 2019). 'Intermediaries' can facilitate circulation, for example, by transferring learning from multiple local projects or experiments to the global niche (Kivimaa et al. 2019). They may also bridge between niche and incumbent actors, developing themselves as transformation progresses (Sovacool et al. 2020a). These actors may ensure that many elements of individual niches are circulating, de-contextualised, and recontextualised in various spatial contexts through designing dedicated interaction between multiple actors across multiple spaces, which facilitates not only exchange of learnings across niches but also between global niches and regimes (Bush et al. 2017; Kivimaa et al. 2019). Recognising and enhancing structural and functional capabilities of systemic intermediaries is an effective way of achieving this TO. Yet, it is important to note that circulation is in many ways unstructured and fluid and can be only partially influenced.

\subsubsection{Institutionalising}

Institutionalising means stabilising shared rules that emerge in niches. It means the global niche is on its way to become a global regime (Geels and Deuten 2006; Fuenfschilling and Truffer 2016) through wide adoption of newly emerged rules that are formalised into rights, routines, and obligations (Streeck and Thelen 2005).

As a TO, institutionalisation can be supported by building consensus within the expanding actor-network and building legitimacy around shared collective definitions, narratives, interpretations, and behaviours (Genus and Iskandarova 2020). This is a delicate process, since it threatens the diverse exploration associated with plural niche-building processes. Establishing a global community of practice (Wenger 1998) around collective and plural 'futures-making' (Wagner and Gałuszka 2020) can be an effective mitigation strategy. Policy actors may also seek support from 'institutional entrepreneurs' who are intermediary actors focussing on not just empowering niches, but also on creating and maintaining shared rules, and building up a constituency behind the new regime through 'institutional work' (van Doren et al. 2020).

EPEs focussed on mainstreaming the niche are often resisted by regime actors. Thus, active engagement of regime actors is needed to build more institutionalised bodies and create space for new institutionalised rules for the niche (Kivimaa and Rogge, 2020).

\subsection{Opening up and unlocking regimes}

While much transitions literature is focussed on niches, recent studies have started to highlight the importance of understanding regime dynamics (Bosman et al. 2014; Leipprand and Flachsland 2018). An important step for transitions is to open and unlock regimes so that niche innovations have 'windows of opportunity' to expand (Schot and Geels 2007). The process of unlocking directly addresses the rigidity of stabilised regime rules which support incrementalism in existing trajectories, keeping the system configuration intact (Geels 2005; Verbong and Geels 2010; Mercure et al. 2016). Even when alternatives are proposed by regime actors, they tend to reaffirm the architecture of the system as it is. To respond 
to the dynamic sustainability challenges, it is necessary to rid the regime of this rigidity and open it for reconfiguration and destablisation (Turnheim and Geels 2012; Kainiemi et al. 2019).

For opening and unlocking regimes, we explore TOs that need to be achieved by regime actors: (1) de-aligning and destabilising, (2) unlearning and deep learning, (3) strengthening regime-niche interactions, and (4) changing the perceptions of landscape pressures.

\subsubsection{De-aligning and destabilising regimes}

Unsustainable regimes can be destabilised when regime actors abandon behaviours, beliefs, and values that hold together the system configuration through 'semi-coherent' rule sets. As formal and informal rules misalign, between system dimensions, the stability of regimes is reduced due to weakened reproduction and flow of resources to keep the system intact (Kainiemi et al. 2019).

De-aligning and destabilising regimes can be a TO, when actors adopt new (innovation) policies (Kivimaa and Kern 2016) or industrial strategy (Karltorp and Sandén 2012) that deliberately challenge and destabilise the existing systems As a result, the new strategies/policies may not align well with other existing system dimensions such as business models or infrastructures. Such de-alignment forces the regime to further open and unlock. Phase-out or exnovation policies link to this TO (David 2017; Rogge and Johnstone 2017) alongside deliberate attempts to disrupt dominant actor-networks or significantly change regime rules (Kivimaa and Kern 2016).

A specific challenge for de-aligning system dimensions can be a strong interconnection between regimes, evolved over time (cf. Konrad et al. 2008). For example, the car-dependent mobility system in the USA is deeply intertwined with the housing system, and the nature of urbanisation and affordable housing in suburbs. De-aligning and destabilising those couplings are difficult due to existing path dependencies.

\subsubsection{Unlearning and deep learning in regimes}

In locked-in regimes, individual actors become entrapped in system dynamics (Sydow et al. 2009). They strongly believe in the viability of the regime for confronting problems and its legitimacy among wider population (Geels 2010). Regimes are stabilised through the conformation of the behaviours, beliefs, and values of regime actors across multiple dimensions. Unlearning of dominant rules by regime actors, in a way that they start questioning existing behaviours, beliefs, values, and norms that are embedded in their existing skills and capabilities is an important element of opening regimes. Van Mierlo and Beers (2020) define unlearning as abandoning obsolete practices and leaving behind old ineffective habits. Unlearning includes an acceptance of risks and uncertainty, and the costs of the reorganisation of the regime in short-tomedium term. Deep learning by regime actors includes experiential social learning about challenges faced by the regime, building on their knowledge of the system and, as a result, their willingness, motivation, and ability to change the system through formal policy processes (Van Poeck et al. 2020; Van Mierlo and Beers, 2020; Vinke-de Kruijf et al. 2020). It can be shaped by local, context-specific challenges or global sustainability discourses (Scholz and Methner 2020). Unlearning and deep learning are complementary processes that innovation policy actors may pursue as a TO for unlocking regimes.

\subsubsection{Strengthening regime-niche interactions}

Regimes can also open by interacting with niches and other regimes (Raven and Verbong 2007; Konrad et al. 2008; Sutherland et al. 2015). Strengthening regime-niche interaction, as a TO, can be achieved through regime actors enabling niche empowerment, intermediary actors challenging incumbents by creating new connections between niches and regimes (Matschoss and Heiskanen 2018), and same actors operating in different but interconnected regimes (Slingerland and Schut 2014; Sutherland et al. 2015; Pekkarinen and Melkas 2019). The initiative of regime actors to reach out to multiple niches is crucial. Being open to alternative ideas proposed by niche actors, the regime actors facilitate change within regimes, ideally resulting in new actor-networks comprising both niche and regime actors. This building of connections can go in two directions. It can seek to support niches to integrate them into the prevailing regime (i.e. 'fit and conform' type of niche empowerment); alternatively, regime and niche actors can mutually support each other for changing the selection environments in favour of disruptive niche innovations ultimately changing the regime (i.e. 'stretch and transform' type of niche empowerment Smith and Raven 2012).

Regime-based transition intermediaries are a specific type of intermediary, empowered to change regimes from within (Kivimaa et al. 2019). They can help linking emerging niche narratives with the socio-political agendas set by regime actors. These intermediaries, despite their regime-based mandates, are influential in building strong and long-lasting relationships between niches and regimes by 'brokering and coordinating partnerships beyond the niche' (Kivimaa and Virkamäki 2014; Bush et al. 2017: 139).

\subsubsection{Changing perceptions of landscape pressures}

The landscape comprises macro-level, exogenous, longterm, and slow-moving trends, such as climate change, or rapid external shocks, like Covid-19, which single actors do not seem to directly influence (van Driel and Schot 2005; Geels 2011; Kungl and Geels 2018). Landscape pressures considerably influence how, in which direction, and with what speed systemic transformations unfold because of their stabilising and/or destabilising power on regimes and niches (Geels 2011). Regime actors are known to react in different ways to 'landscape inertia' (trends, opportunities, and threats), depending on their political ideology, cultural understandings, societal preferences, and lifestyle (Li and Strachan 2017). In that way, dominant regime shapes what is perceived as landscape pressures. For example, the automobility system has changed the landscape by contributing to trends towards individualisation, urbanisation and industrialisation, and the severity of climate change and the state of the environment. Thus, landscape pressures are also exacerbated and created by regimes (and not exogenous).

The ways in which landscape pressures are perceived by regime actors is uneven and varies across contexts (Hansen and Coenen 2015). It may comprise multiple and diverging trends. When regime actors begin to see alignments between multiple external pressures, it could create an 'overwhelming effect', leading to altered perceptions (Turnheim and Geels 2012) and what is deemed 'relevant'. Explicit attention to changing perceptions about diverse landscape pressures 
is a TO, with significant implications on decision-making, (re)distribution of resources, and commitments to unlocking regimes.

\section{Case studies}

We present two cases of currently ongoing transformative change: MaaS in Finland and speciality coffee in Colombia. We sought to make visible the emergence of TOs, while it must be noted that these are part of longer narratives of events reported elsewhere (Arond et al. 2017; Kivimaa and Rogge 2020). Let us introduce both cases briefly. Results of our analysis are summarised in Table 2. Subsequently we provide an analysis of the results.

MaaS has since 2014 developed as a niche in Finland, with support from both regime and niche actors. They have perceived a need to move from individual ownership of cars to personalised mobility services to reduce the environmental impacts of transport and improve access for people who cannot afford to own a car. The concept of MaaS, proposed by a championing niche actor, focussed on optimising the connection between private vehicles and public transport via shared mobility services. The idea has benefitted from refocussing and reorganising national-level public governance since the early 2000s in response to landscape developments such as digitalisation, urbanisation, ageing population, and climate change, while innovation and transport policy actors have actively supported the early stages. In Finland, MaaS is typically defined by key niche actors as specific 'packaged offerings' with intermodal planning, booking, and payment components, comprising multiple transport modes. As such, the MaaS niche challenges the dominant transport regime built around individual motorised transport.

In some Finnish cities, public transport operators have been unwelcoming for MaaS providers to appear on their 'turf'. They have been reluctant to allow third-party ticket sales, hindering the upscaling of MaaS. Taxi providers have opposed change, where multiple companies can provide taxi services in a given area, increasing competition. The enforcement of the Transport Service Act has been strengthened by threats of penalty payments issued by the Transport and Communications agency, but the underlying tensions have not yet been solved. Covid-19 has slowed down the further development of MaaS.

The coffee industry is among the most important export sectors in Colombia, providing a living for approximately 800,000 people. Until the 1990 s, the Colombian coffee sector was firmly wedded to a commodity model of production: farmers receive a fixed price for a standardised quality of coffee bean that is mainly used for exports, with smaller and off-colour beans sold for domestic consumption. This system was thrown into disarray in the 1990s with a number of landscape developments, in particular the breakup of the International Coffee Organization, the associated International Coffee Agreement, and the commodity-based international system for coffee production and supply. Consequently, the speciality coffee niche emerged, promoted by international organisations such as Fairtrade and the Rainforest Alliance, representing an alternative international system of certification for coffee production. Its transformative feature is a vision of coffee that is in harmony with the environment and has a strong commitment to local social development.
Preceding the crisis, research into alternatives by the incumbent actor in Colombia, the National Federation of Coffee producers (FNC), remained marginal and the FNC did not undertake serious investment into building niches for what is referred to as specialty coffee. Consequently, the Colombian coffee system remained locked into a commodity model (Echevarria et al. 2014: 5). Under the commodity system, the farmer was largely disengaged and alienated from his/her produce with little opportunity to improve the quality of the product and few incentives to improve environmental practices. By building the specialty coffee niche, producers moved from 'producing a coffee bean to producing a drink'. Farmers learnt to become tasters and developed knowledge about different preparation methods. They also developed skills around coffee washing, fermenting, and drying and to follow certifications that demand careful implementation of environmentally-sound practices. More disruptive conceptualisations of the value chain have yet to emerge.

Table 2 shows our analysis regarding the extent to which we have detected TOs in these two processes. We do not seek to provide a definitive and comprehensive appraisal of the cases and the extent of their transformation. Even with stylised cases, the salience of the TOs we identified is clearly visible. For the case studies, the authors made assessments of the quality of the TOs, by calling them substantial for example, based on all collected case material (see Section 2 for overview). When applied in real-time EPEs, these quality assessments should be done together with the actors in a formative evaluation process. In that process, the focus is on organising a discussion about outcomes to reflect and induce learning among actors on how to improve (Molas-Gallart et al. 2020).

The MaaS case shows that many TOs are worked upon by several actors, leading to a robust process of 'niche development' on all four outcomes: shielding, learning, networking, and expectation dynamics. Robust means that all processes were of sufficient quality to lead to a niche that is clearly recognisable as such by all actors. This process of niche building was enabled by a process of 'regime opening and unlocking', mainly by transport and innovation policy dimensions at the national level. However, this process has not extended significantly to city-level policymaking in Finland. The case is characterised by early and active participation by national regime actors, in particular the national innovation agency (Tekes, subsequently Business Finland) and the Ministry of Transport and Communications. These actors had created several EPEs such as the New Transport Policy Club, the Traffic Lab, and Tekes's MaaS Programme. The development intertwined with major organisational changes in the administration for transport and communications and led to a significant regulatory change in the transport sector. These changes began to destabilise the operational context for many transport-sector actors and removed barriers for niche expansion. However, while the policy changes aimed to influence many regime dimensions, changes in the other regime dimensions, especially in the preferences of mobility users, and the mobility culture have not yet substantially changed. Most 'niche expansion' outcomes were also insufficiently covered.

The MaaS case illustrates how development in multiple TOs can happen in parallel and is not a linear, sequential process. The process was initiated in dialogue between niche and regime actors, who searched for new opportunities in response to intensifying landscape pressures on 
Table 2. TOs in the two case studies.

Transformative outcome
Colombian coffee production
Building and nurturing niches

TO1 Shielding

TO2 Learning

TO4 Networking

TO4

Navigating

expectations

\section{Innovation funding}

A year after the MaaS idea was conceptualised, in 2015, innovation agency Tekes established a MaaS programme, including a two-stage call to fund MaaS operators: (1) pre-studies that plan real MaaS pilots and co-design them with potential partners and (2) concrete test beds where the projects included collaborators and external investors. MaaS businesses regarded this funding instrumental. Some Tekes officials called it experimental, being initiated bottom-up and bypassing the usual bureaucratic process of programme setting.

In 2018, Business Finland (previously Tekes) awarded subordinated loans via its new Growth Motor Funding, an experimental policy for funding networks of companies, in total 28.4 million euros to five different companies, two related to $\mathrm{MaaS}$

Collaborative learning via supportive EPEs

In 2014, the ministry established a Traffic Lab operating as an umbrella for public-private experimentation around intelligent transport systems. It was a space for learning about technical solutions and how to change people's mobility assumptions, preferences, and practices. It nurtured a variety of niche developments; being was coordinated by the transport administration.

Tekes's MaaS Programme was succeeded by a network among multiple companies (including large companies in the telecoms sector, Helsinki Regional Transport, and the taxi union) that explored what an actual MaaS operator would look like.

An incumbent telecommunications company, Telia, launched a $\mathrm{MaaS}$ app in one region combining national rail services and local taxi services (broadening learning)

Public-private networking followed up by new company networks

In 2004, the ministry encouraged the establishment of a collaboration network, Intelligent Transport Systems Finland (ITS Finland), an association, including civil servants, companies, and researchers. Its director and chairman developed the MaaS concept in a discussion with members.

In 2014, a group of actors, including ITS Finland and the City of Helsinki and the ministry began creating a vision for MaaS. This was a next step in the niche-building process, building on regime actors working with niche actors. It consisted of a limited set of interactions.

Expanding networking in 2015 via Tekes's MaaS Programme and the succeeding network of companies

Active role of public agencies and public-private networks in navigating expectations

ITS Finland voicing expectations of future transport systems from 2004.

In 2014, collaboration between ITS Finland, City of Helsinki and the ministry to create a vision and a proposal for MaaS. Initially, in 2014 in Tekes, MaaS was a small, informal initiative; a campaign to activate new companies to begin developing new technologies and services. A joint campaign of Tekes and the ministry organised round tables on themes linked to MaaS, inviting companies to discuss the vision for MaaS, needs of municipalities, public transport providers, designers to think about service design, and some focussed on logistics. Some niche actors viewed Tekes as a thought leader who made sure that MaaS advanced.

Tekes's MaaS Programme in 2015

\section{A certified niche market}

The first Rainforest Alliance farm was certified in Guatemala in 1995. By 2000 the specialty coffee market had grown to $\$ 8$ billion. This market was an important passive shielding for small farmers who would adopt speciality coffee as an alternative to the commodity model of production

Learning via bottom-up search process

Niche actors in other countries had been experimenting successfully with alternative sustainable visions of coffee value chains.

This adoption process became a search process for nurturing the speciality coffee niche. In this process, existing farmers experienced deep learning individually and collectively. For small farmers this was critical in helping to reset expectations concerning their role in coffee production

Incentives to form networks of small farmers around specialty coffee

At the collective level, farmers were incentivised to organise themselves into cooperatives that are crucial to integrate knowledge and build trust. These cooperatives built new networks with intermediaries, consumers, and other farmers

Emerging expectations with a range of benefits The emerging expectation of cooperative leaders and some other actors along the speciality coffee value chain (e.g. some certification setters and users) was that speciality coffee would prioritise small-scale producers and help articulate the importance of greater access by smallholders to training, education, finance, and access to market trade shows. This would trigger a sense of belonging of small producers with their sector that would engender a greater stake in the future of the sector, which then would lead to greater stewardship of the land and education of the children in the new methods of the industry. Thus, new expectations were expressed for regime development (inability of dominant practice to come up with a solution) and the potential of the specialty coffee niche were knit together, which initiated a self-fulling prophecy. 
Table 2. (Continued)

Transformative outcome

MaaS in Finland
Colombian coffee production

Formation of cooperatives prompted new collective voices to express more disruptive notions of coffee value chains. These include re-imagining coffee chains where farmer knowledge/need in the coffee value chain are legitimised. Value chains are re-thought, where farmers have a major say in defining criteria of certifications (leading to experimentation whereby farmers can choose who buys their coffee)

Expanding and mainstreaming niches

TO5 Upscaling Growing companies and supportive funding

From 2016, different companies began operating with MaaS

pilots. A new start-up, MaaS Global, began with pilots in

Helsinki, Antwerp, and Birmingham.

Business Finland Growth Motor Funding supporting upscaling

TO6 Replicating

Public funding for replication

Business Finland Growth Motor Funding supporting replication

TO7 Circulating

Organic circulation via people

Circulation of knowledge via people changing jobs between the ministry, ITS Finland, and MaaS operators

TO8 Institutionalising

International niche organisation and regulatory change institutionalising the niche

In 2016, the European MaaS Alliance was created, aiming for the consolidation of niche efforts at the European level (beginnings of institutionalising). The founding members included regime actors, such as the Finnish Ministry of Transport and Siemens, and niche actors, such as Maas Global and the ITS Europe network.

A major regulatory renewal, the Transport Service Act in 2017, required public transport providers to open data and electronic access to timetables, prices, and ticket sales, allowing third parties (MaaS operators) to sell transport tickets

Opening up and unlocking regimes

TO9 De-aligning and

De-aligning to a changing administration

destabilising

After the MaaS programme ended, funding for MaaS-related projects was integrated into Tekes's ongoing Smart City Programme (2014-7).

During 2016-9, public transport administration went through two stages of organisational changes; first, the full integration of Transport and Communications in the Ministry and later its agencies.

Transport Service Act (2017) was described by many actors as groundbreaking and unique transport-sector legislation globally, disrupting the regulatory side of the transport regime

TO10 Unlearning and deep learning in regimes
Upscaling support from a niche association In 2004, the first smallholder coffee farmer association was established in Huila with the support of the FNC. This was a result of a process of actively circulating and replicating knowledge from different experiments,

See above

See above

Initialisation via a regime actor support and certification In 2002, the FNC created Procafecol and Juan Valdes coffee, providing a boost to speciality coffees.

The niche was institutionalised through the adoption of certifications: the Utz Kapeh in 2002, the Nestle's AAA Sustainable Quality Programme with the Rainforest alliance in 2003, and the participative agricultural innovation farms certification in 2014. Colombia's speciality coffee production grew from $2 \%$ of the total coffee exports in 2000 to $28 \%$ in 2013 (Echevarria et al. 2014). In 2014, Huila reported a total of 101,000 coffee farms producing $17.4 \%$ of the Colombian coffee harvest passing the $16 \%$ threshold for niche acceleration adoption (FNC 2014)

Destabilisation emerging from the ground up

Pressure on the FNC to scale up the search for alternatives to the existing system emerged from the collapse of international coffee prices and from social movements and protests of more than 100,000 farmers with small lands in the late 1990s. These took place in ten regional departments with marches and blockage of principal roads. The protests sent a clear message that the system was misaligned (Cruz-Rodríguez 2013: 145) and speeded up the search and implementation of changes to the governance arrangements, thus opening up and unlocking of the national coffee regime

A regime actor organising unlearning

FNC created new extension agents that were crucial in actively phasing out (unlearn) unsustainable practices such as non-sustainable discard of coffee shells. Previous practices were re-assessed and new production techniques that are sustainable with the environment were introduced leading to substantial upscaling
Focussed unlearning via experimental policymaking

During 2007-2011, transport policy underwent new developments, e.g. two strategies for intelligent transport and organisational changes leading to multi-modal agencies. In 2012, the Minister for Transport established the New Transport Policy Club, an experimental arena for Years 2012-4 to renew transport policy and address the challenges of climate change, automation, and servitisation. It aimed at generating deep learning across sectors, extending beyond the public sector, leading to the beginnings of opening up and unlocking of the mobility and communication regimes. In one of the meetings, the Director of ITS Finland introduced the idea of MaaS, drawing from thinking in the telecommunications sector. This roused the interest of a regime actor, a high-level civil servant, and many others, who began advancing the idea. As a result, in 2014, the ministry launched a proposal on MaaS 
Table 2. (Continued)

Transformative

outcome MaaS in Finland

TO11 Strengthen-

ing regime-niche

interactions
Colombian coffee production

The main regime actor in the Colombian coffee sector, the FNC, eventually also scaled up work on speciality coffee. The coffee sector increasingly changed and became a more diverse value chain with NGOs, specialised growers (e.g. women's groups), and buyers establishing their own local distribution chains and working with the FNC. In 2006, the FNC established the 'Women's Coffee programme' by means of an integral programme of gender equality to support empowerment of women in all areas related to coffee production, participation in the FNC, and community leadership

Collapse of international coffee prices and rise of social movements (see TO9) climate change, digitalisation and automation, and economic developments. Gradually, a more transformative path developed, fuelled by expectation and network dynamics. Niche actors working from within the dominant regime managed to carve out a niche for a radical substitute for the dominant mobility regime, challenging the clear separation between public and private transport provision and individual car ownership.

The Colombia specialty coffee case shows all TOs leading to robust 'niche building': shielding, networking, learning, and expectation dynamics. The shielding, however, was not provided by national or local policymaking, but by influential niche actors working at different multi-scalar levels (production, consumption and logistics) to develop an alternative sustainable vision of the value chain that is capable of integrating local producers at the grassroots level. The subsequent learning was deep, because many assumptions about coffee production were challenged and expectations were opened for new futures, questioning a business-as-usual response. Farmers changed their behaviour, beliefs, and values during the process. For the farmer, in many ways, the journey followed a 'stretch-and-transform' pattern.

Due to landscape changes, it had become clear that the existing regime was clearly no longer fit for purpose and regime actors were willing to reorient their beliefs and behaviours following a shock fall in prices. New national and international networks emerged among farmers and supporting institutions. This led to a process of 'niche expansion'. Farmers circulated their ideas and experiences, building new platforms. They replicated experiments that could be institutionalised through international certification schemes. Although the traditional coffee 'regime opened' for change, many farmers had to unlearn existing practices and change their perception of landscape developments. While regime actors invested in the specialty niche, this did not replace the dominant regime. Currently, after 15-20 years of development, specialty and commodity coffee coexist, with the latter serving other markets. The case is characterised by bottom-up actions by farmers, but lacked major policy involvement and engagement with STI policy actors to support the new specialised coffee niche.

The two cases illustrate very different context and application of TOs. Whereas in the context of Finland, TOs involved coordinated government activities and collaborative networks, the Colombian case is more about bottom-up and market-driven niche building and mainstreaming process, combined with actors working in different scales, locally and internationally in the opening up and unlocking regime process.

\section{Lessons from cases for transformative innovation policy}

Both cases deliver clear lessons for TIP and the use of TOs. We summarise these lessons in the following five points.

First, the cases confirm our proposed starting point on TIP: transformation is ongoing, even in cases where innovation policymaking is absent or connects only later to the process. Innovation policy and STI actors should actively engage with such ongoing transformation processes, and innovation policy should be designed, implemented, and evaluated from this perspective (cf. Kuhlmann and Rip 2018). A focus on TOs can help to make such policies more transformative.

Second, TOs place explicit attention on (i.e. make visible) the processes required by transformation and enable STI actors to actively work with transformation. Missing outcomes can be identified and addressed. When TOs are used in designing, implementing, and evaluating STI projects, programmes, and policies, we expect actors to deliberate which outcomes they want to prioritise and when. This is a reflexive process that requires actors to collectively reflect on their own actions and possible and desired consequences (Weber and Rohracher 2012). In this process, STI actors need to realise that these outcomes do not result from one or two policy interventions. As our case studies clearly show, they emerge from a complex set of actions unfolding over longer periods. Yet they may help STI actors to stay focussed on a systematic approach, building on an understanding that they may have to coordinate with other policy actors to realise outcomes. This coordination may be partial and selective, but the overall coordination is elusive and may also lead to a fit-and-conform pattern.

Third, the engagement with outcomes is not only about developing specific outcomes but also about stretching them. For example, learning may be deep, but perhaps it can 
be made deeper. Or networks can be broadened by making them more inclusive. To assess whether and how this is true, STI agents should engage in a reflexive deliberation process with all actors improving the quality of the outcomes.

Fourth, the TOs proposed here emphasise the importance of adding mechanisms to innovation policy that address the opening and unlocking of socio-technical regimes. This resonates with earlier propositions for innovation policy to consider also destabilising or disruptive effects alongside niche building and expansion (Kivimaa and Kern 2016). Both cases provide insights into the relationship between regime destabilisation and experimentation. For example, in the MaaS case the Ministry for Transport and Communications developed into an STI actor, also engaging with the outcomes associated with regime unlocking. The specific circumstance in which regime destabilisation happens is, however, unpredictable, unforeseen, and often triggered by endogenous or exogenous crises that escape the authority of any actor. Yet, the willingness of STI actors to engage in those circumstances by framing changes as windows of opportunity and using them to create policies for regime openings is important.

Fifth and finally, the ways in which TOs can be achieved are highly context specific. Both cases presented are heavily embedded in their local, regional, and national socioeconomic and political settings. For instance, in the context of Colombia, shielding was provided by the agency of local coffee producers who were included in a global value chain and were acting across multiple scales. In contrast, experimentation with MaaS was a national-policy-led process that fitted the policy agenda, which had emerged in Finland after the future of Nokia had deteriorated. Finland needed to look for other use of its ICT capabilities.

\section{Conclusion}

In the face of persistent social and ecological challenges, new approaches to STI policy are necessary. Globally, STI and other agents of change are already experimenting with challenge-led innovation policies, which are ambitious in achieving SDGs, yet lack appropriate implementation and evaluation processes in order to mitigate the issues of coordination, lack of reflexivity, and inclusion. The TIP lens offers a critical entry point for guiding the operations of STI and other change agents towards more transformative results.

Sustainability transitions literature, on which the theorisation of TIP is based, offers a wealth of knowledge about systemic transformation and transition dynamics. Our framework offers a new synthesis in a way that is accessible to policy practitioners. The framework of twelve TOs operationalises key insights from that literature to guide the practices of STI agents working towards enabling transformations. The outcomes are categorised across three spatially bounded macro-processes that can facilitate transformations: (1) building and nurturing niches, (2) expanding and mainstreaming niches, and (3) opening up and unlocking regimes. Within the process of building and nurturing niches, shielding, learning, networking, and navigating expectations are the TOs. For expanding and mainstreaming niches, upscaling, replicating, circulating, and institutionalising are the outcomes. The final four TOs within opening and unlocking regimes are de-aligning and destabilising, unlearning and deep learning, strengthening regime-niche interactions, and changing perceptions of landscape pressures.

These outcomes can be achieved through EPEs that foster continuous monitoring, evaluation, and reflexivity in the conduct of actors for transformative change. In this way, TOs should be used as a reflexive action framework, rather than a prescriptive step-by-step guide of how to achieve transformations.

The application of the TOs framework to reinterpret two case studies-MaaS in Finland and specialty coffee in Colombia-confirmed that, to transform systems, STI agencies need to attend to opening up for more radical transformations 'within' the regimes, instead of just initiating new niche projects and hoping they would scale. Our results suggest that these activities are also experimental and require specific provisions not easily attainable through conventional policy. This is a significant departure from both traditional transitions theories and innovation policy assumptions that experiments are primarily relevant for novelty creation in building niches. Here, we advocate for an explicit experimental culture that recognises and engages the various societal experiments within and beyond government, which leverages specific forms of evaluation to make the outcomes of policy practices to be more transformative.

Practically, which sub-set of TOs to prioritise with a given policy engagement depends on the status of the unfolding transformations. Given their complexity, we assume that it may be impossible to 'assess' this status objectively ex-ante. TOs, therefore, serve as a process-oriented heuristic with which to interrogate transformation processes through the cocreation process of TIPC in order to support and improve the transformational efforts of current and future TIPC members. In future research and policy actions, it would be important to identify and test which TOs are relevant in a particular system and in particular context, how to improve the quality of the outcomes, and how to stretch existing actions to achieve more TOs.

\section{Funding}

The Transformative Innovation Policy Consortium (TIPC) provided funding for this paper. In addition, P.K. acknowledges funding from the Academy of Finland (decision number 322667) for her contribution to the paper.

Conflict of interest. There are no conflicts of interest.

\section{Acknowledgements}

We would like to thank the TIP Consortium, MOTION, and Deep transitions teams for their continuous support for this research. We would like to mention Carla Alvial Palavicino, Paulina Terrazas, Christoph Brodnik, Oscar Romero Goyeneche, Matthias Weber, Alexandra Boni, Jordi MolasGallart, and Ed Steinmueller for their contributions towards earlier work in conceptualising the theory and methods presented in this paper. We thank Geraldine Bloomfield and Jenny Witte for their work on the graphics and communications on this framework. We thank all stakeholders involved in the workshop and interviews carried out for the case studies. We thank Ruth Buckley-Salmon for her help with the reference list and proofreading. We extend our gratitude to the 
two anonymous reviewers for the comments that immensely helped in improving the paper.

\section{Notes}

1. Such change processes are often called a transformation or transition. Here, we use the terms interchangeably. Both concepts refer to a system change, although the meaning of a system may differ, from socio-technical to socio-ecological systems.

2. Current members are innovation ministries and funding agencies from Colombia, Finland, Norway, South Africa, and Sweden. There are additional associate programmes in China, Brazil, Senegal, Ghana, and Kenya. The consortium is coordinated by the Science Policy Research Unit at the University of Sussex, in collaboration with the Centre for Global Challenges at Utrecht University and INGENIO, at Universidad Politécnica de Valencia. See www.tipconsortium.net.

3. The term co-creation often refers to co-creation with citizens (e.g. Voorberg et al. 2015). We used this term to refer to the transdisciplinary process of TIPC, as it was the term policymakers themselves often referred to. It reflected the unusual situation where these actors, used to fund projects, were involved in establishing a joint search process with researchers on how to define and implement TIP.

4. At the time of this research, Finland, Sweden, Norway, South Africa, Colombia, and Mexico (and China, Kenya, Ghana, and Senegal as an associated member) were active in the consortium.

5. Note that the notion of outcomes is also used in formative evaluation and theory of changes approach that comes with it. There, it refers to a change in behaviour or people and organisations. TOs can therefore be seen as a specific interpretation of what counts as outcomes in formative evaluation (Molas-Gallart et al. 2020).

\section{References}

Arond, E., Ramirez, M., and Yepes, A. (2017) 'Transformative Innovation Learning History: Colombia Transformative Innovation Policy in/for Specialty Coffees'. Transformative Innovation Policy Consortium. <https://www.tipconsortium.net/wp-content/uploads/ 2019/05/Transformative-Innovation-Learning-History-Colombia-.RK1.pdf>.

Avelino, F., Dumitru, A., Cipolla, C., et al. (2019) 'Translocal Empowerment in Transformative Social Innovation Networks', European Planning Studies, 28: 955-77.

Bauer, F. and Fuenfschilling, L. (2019) 'Local Initiatives and Global regimes-Multi-scalar Transition Dynamics in the Chemical Industry', Journal of Cleaner Production, 216: 172-83.

Binz, C., Coenen, L., Murphy, J. T., et al. (2020) 'Geographies of transition-From Topical Concerns to Theoretical Engagement: A Commentary on the Transitions Research Agenda', Environmental Innovation and Societal Transitions, 34: 1-3.

Boon, W. and Edler, J. (2018) 'Demand, Challenges, and Innovation. Making Sense of New Trends in Innovation Policy', Science and Public Policy, 45: 435-47.

Boon, W. P., Moors, E. H., and Meijer, A. J. (2014) 'Exploring Dynamics and Strategies of Niche Protection', Research Policy, 43: 792-803.

Borghei, B. B. and Magnusson, T. (2018) 'Niche Aggregation through Cumulative Learning: A Study of Multiple Electric Bus Projects', Environmental Innovation and Societal Transitions, 28: 108-21.

Borrás, S. and Laatsit, M. (2019) 'Towards System Oriented Innovation Policy Evaluation? Evidence from EU28 Member States', Research Policy, 48: 312-21.

Borup, M., Brown, N., Konrad, K., et al. (2006) 'The Sociology of Expectations in Science and Technology', Technology Analysis and Strategic Management, 18: 285-98.
Bos, J. J., Brown, R. R., and Farrelly, M. A. (2013) 'A Design Framework for Creating Social Learning Situations', Global Environmental Change, 23: 398-412.

Bosman, R., Loorbach, D., Frantzeskaki, N., et al. (2014) 'Discursive Regime Dynamics in the Dutch Energy Transition', Environmental Innovation and Societal Transitions, 13: 45-59.

Brown, N. and Michael, M. (2003) 'A Sociology of Expectations: Retrospecting Prospects and Prospecting Retrospects', Technology Analysis and Strategic Management, 15: 3-18.

Budde, B., Alkemade, F., and Weber, K. M. (2012) 'Expectations as a Key to Understanding Actor Strategies in the Field of Fuel Cell and Hydrogen Vehicles', Technological Forecasting and Social Change, 79: 1072-83.

Budde, B. and Konrad, K. (2019) 'Tentative Governing of Fuel Cell Innovation in a Dynamic Network of Expectations', Research Policy, 48: 1098-112.

Bush, R. E., Bale, C. S. E., Powell, M., et al. (2017) 'The Role of Intermediaries in Low Carbon Transitions - Empowering Innovations to Unlock District Heating in the UK', Journal of Cleaner Production, 148: 137-47.

Carvalho, L. and Lazzerini, I. (2018) ' 3 - Anchoring and Mobility of Local Energy Concepts', in Turnheim B., Kivimaa P., and Berkhout F. (eds) Innovating Climate Governance: Moving Beyond Experiments, pp. 49-68. Cambridge: Cambridge University Press.

Coenen, L., Raven, R., and Verbong, G. (2010) 'Local Niche Experimentation in Energy Transitions: A Theoretical and Empirical Exploration of Proximity Advantages and Disadvantages', Technology in Society, 32: 295-302.

Coenen, L., and Truffer, B. (2012) "Places and Spaces of Sustainability transitions: Geographical Contributions to an Emerging research and policy field", European Planning Studies, 20: 367-74.

Cruz-Rodríguez, E. (2013) "'We are all children of Coffee": Political Sociology of the National Strike Coffee', Entramado, 9: 138-58.

Danermark, B., Ekström, M., and Karlsson, J. C. (2002) Explaining Society: Critical Realism in the Social Sciences. Oxfordshire: Routledge.

David, M. (2017) 'Moving beyond the Heuristic of Creative Destruction: Targeting Exnovation with Policy Mixes for Energy Transitions', Energy Research and Social Science, 33: 138-46.

Delina, L. and Janetos, A. (2018) 'Cosmopolitan, Dynamic, and Contested Energy Futures: Navigating the Pluralities and Polarities in the Energy Systems of Tomorrow', Energy Research and Social Science, 35: $1-10$

Diercks, G., Larsen, H., and Steward, F. (2019) 'Transformative Innovation Policy: Addressing Variety in an Emerging Policy Paradigm', Research Policy, 48: 880-94.

Dignum, M., Dorst, H., van Schie, M., et al. (2020) 'Nurturing Nature: Exploring Socio-spatial Conditions for Urban Experimentation', Environmental Innovation and Societal Transitions, 34: $7-25$.

Echevarria, J. J., Esguerra, P., McAllister, D., et al. (2014) 'Informe De La Misión De Estudios Para La Competitividad De La Caficultura En Colombia', Resumen Ejecutivo: Universidad del Rosario.

Edler, J. and Fagerberg, J. (2017) 'Innovation Policy: What, Why, and How', Oxford Review of Economic Policy, 33: 2-23.

Elzen, B., Geels, F. W., and Green, K. (2004) System Innovation and the Transition to Sustainability: Theory, Evidence and Policy. Cheltenham: Edward Elgar.

Feola, G. and Nunes, R. (2014) 'Success and Failure of Grassroots Innovations for Addressing Climate Change: The Case of the Transition Movement', Global Environmental Change, 24: 232-50.

Fuenfschilling, L. and Truffer, B. (2016) 'The Interplay of Institutions, Actors and Technologies in Socio-technical Systems - An Analysis of Transformations in the Australian Urban Water Sector', Technological Forecasting and Social Change, 103: 298-312.

Geels, F. (2005) 'Technological Transitions and System Innovations: A Co-evolutionary and Socio-technical Analysis’. 
Geels, F. and Deuten, J. J. (2006) 'Local and Global Dynamics in Technological Development: A Socio-cognitive Perspective on Knowledge Flows and Lessons from Reinforced Concrete', Science and Public Policy, 33: 265-75.

Geels, F. W. (2010) 'Ontologies, Socio-technical Transitions (to Sustainability), and the Multi-level Perspective', Research Policy, 39: 495-510.

(2011) 'The Multi-level Perspective on Sustainability Transitions: Responses to Seven Criticisms', Environmental Innovation and Societal Transitions, 1: 24-40.

Geels, F. W. and Johnson, V. (2018) 'Towards a Modular and Temporal Understanding of System Diffusion: Adoption Models and Sociotechnical Theories Applied to Austrian Biomass District-heating (1979-2013)', Energy Research and Social Science, 38: 138-53.

Geels, F. W. (2002) 'Technological transitions as evolutionary Reconfiguration Processes: A Multi-level Perspective and a Case-study', Research Policy, 31: 1257-74.

Geels, F. W., Kern, F., Fuchs, G., et al. (2016) 'The Enactment of Socio-technical Transition Pathways: A Reformulated Typology and A Comparative Multi-level Analysis of the German and UK Lowcarbon Electricity Transitions (1990-2014)', Research Policy, 45: 896-913.

Genus, A. and Iskandarova, M. (2020) 'Transforming the Energy System? Technology and Organisational Legitimacy and the Institutionalisation of Community Renewable Energy', Renewable and Sustainable Energy Reviews, 125: 109795.

Ghosh, B. and Schot, J. (2019) 'Towards a Novel Regime Change Framework: Studying Mobility Transitions in Public Transport Regimes in an Indian Megacity', Energy Research and Social Science, 51: 82-95.

Ghosh, B. and Sharmeen, F. (2021) Understanding Cycling Regime Transition and Inequality in the Global South: Case Study of an Indian Megacity, Cycling. Societies: Innovations, Inequalities and Governance. Oxfordshire: Routledge.

Gibbs, D., and O’Neill, K. (2015) 'Building a Green Economy? Sustainability Transitions in the UK Building Sector', Geoforum, 59: 133-41.

Gosens, J., Binz, C., and Lema, R. (2020) 'China's Role in the Next Phase of the Energy Transition: Contributions to Global Niche Formation in the Concentrated Solar Power Sector', Environmental Innovation and Societal Transitions, 34: 61-75.

Grillitsch, M., Hansen, T., Coenen, L., et al. (2019) 'Innovation Policy for System-wide Transformation: The Case of Strategic Innovation Programmes (SIPs) in Sweden', Research Policy, 48: 1048-61.

Grin, J., Rotmans, J., and Schot, J. (2010) Transitions to Sustainable Development: New Directions in the Study of Long Term Transformative Change (Routledge Studies in Sustainability Transitions), 1st edn. Oxfordshire: Routledge.

Hansen, T. and Coenen, L. (2015) 'The Geography of Sustainability Transitions: Review, Synthesis and Reflections on an Emergent Research Field', Environmental Innovation and Societal Transitions, 17: 92-109.

Hansen, U. E. and Nygaard, I. (2013) 'Transnational Linkages and Sustainable Transitions in Emerging Countries: Exploring the Role of Donor Interventions in Niche Development', Environmental Innovation and Societal Transitions, 8: 1-19.

Hölscher, K., Frantzeskaki, N., McPhearson, T., and Loorbach, D. (2019) 'Tales of transforming cities: Transformative climate governance capacities in New York City, US and Rotterdam, Netherlands', Journal of environmental management, 231: 843-57.

Jolly, S., Raven, R., and Romijn, H. (2012) 'Upscaling of Business Model Experiments in Off-grid PV Solar Energy in India', Sustainability Science, 7: 199-212.

Jørgensen, U. (2012) 'Mapping and Navigating Transitions - The Multilevel Perspective Compared with Arenas of Development', Research Policy, 41: 996-1010.
Kainiemi, L., Eloneva, S., and Levänen, J. (2019) 'Transition towards a Decentralised Energy System: Analysing Prospects for Innovation Facilitation and Regime Destabilisation in Finland', Technology Analysis and Strategic Management, 31: 1003-15.

Kanger, L. and Kivimaa, P. (2017) 'Transformative Innovation Learning History: Finland. The Emergence and Consolidation of Mobility-asa-service in Finland', TIPC Working Paper. Brighton.

Karltorp, K. and Sandén, B. A. (2012) 'Explaining Regime Destabilisation in the Pulp and Paper Industry', Environmental Innovation and Societal Transitions, 2: 66-81.

Kivimaa, P., Boon, W., Hyysalo, S., et al. (2019) 'Towards a Typology of Intermediaries in Sustainability Transitions: A Systematic Review and A Research Agenda', Research Policy, 48: 1062-75.

Kivimaa, P. and Kern, F. (2016) 'Creative Destruction or Mere Niche Support? Innovation Policy Mixes for Sustainability Transitions', Research Policy, 45: 205-17.

Kivimaa, P., and Rogge, K. S. (2020) Interplay of Policy Experimentation and Institutional Change in Transformative Policy Mixes: The Case of Mobility as a Service in Finland SWPS 2020-17, <https:// ssrn.com/abstract $=3712545>$.

Kivimaa, P. and Virkamäki, V. (2014) 'Policy Mixes, Policy Interplay and Low Carbon Transitions: The Case of Passenger Transport in Finland', Environmental Policy and Governance, 24: 28-41.

Konrad, K. (2006) 'The Social Dynamics of Expectations: The Interaction of Collective and Actor-specific Expectations on Electronic Commerce and Interactive Television', Technology Analysis and Strategic Management, 18: 429-44.

Konrad, K., Markard, J., Ruef, A., et al. (2012) 'Strategic Responses to Fuel Cell Hype and Disappointment', Technological Forecasting and Social Change, 79: 1084-98.

Konrad, K., Truffer, B., and Voß, J. P. (2008) 'Multi-Regime Dynamics in the Analysis of Sectoral Transformation Potentials: Evidence from German Utility Sectors', Journal of Cleaner Production, 16: 1190202.

Leipprand, A. and Flachsland, C. (2018) 'Regime Destabilization in Energy Transitions: The German Debate on the Future of Coal', Energy Research and Social Science, 40: 190-204.

Li, F. G. N. and Strachan, N. (2017) 'Modelling Energy Transitions for Climate Targets under Landscape and Actor Inertia', Environmental Innovation and Societal Transitions, 24: 106-29.

Loorbach, D., Frantzeskaki, N., and Thissen, W. (2011) 'A Transition Research Perspective on Governance for Sustainability', in Carlo C., Jaeger J., Tàbara D., Jaeger J (eds) European Research on Sustainable Development, pp. 73-89. Berlin, Heidelberg: Springer.

Matschoss, K. and Heiskanen, E. (2018) 'Innovation Intermediary Challenging the Energy Incumbent: Enactment of Local Sociotechnical Transition Pathways by Destabilisation of Regime Rules', Technology Analysis and Strategic Management, 30: 1455-69.

Mauser, W., Klepper, G., Rice, M., et al. (2013) 'Transdisciplinary Global Change Research: The Co-creation of Knowledge for Sustainability', Current Opinion in Environmental Sustainability, 5: 420-31.

Mazzucato, M. (2018) 'Mission-oriented Innovation Policies: Challenges and Opportunities', Industrial and Corporate Change, 27: 803-15.

Meelen, T., Truffer, B., and Schwanen, T. (2019) 'Virtual user Communities Contributing to Upscaling Innovations in Transitions: The case of Electric Vehicles', Environmental Innovation and Societal Transitions, 31: 96-109.

Mercure, J. F., Pollitt, H., Bassi, A. M., et al. (2016) 'Modelling Complex Systems of Heterogeneous Agents to Better Design Sustainability Transitions Policy', Global Environmental Change, 37: 102-15.

Mezirow, J. (2000) Learning as Transformation: Critical Perspectives on a Theory in Progress. The Jossey-Bass Higher and Adult Education Series. San Francisco, CA: Jossey-Bass Publishers. 
Molas-Gallart, J., Boni, A., Schot, J., et al. (2020) A Formative Approach to the Evaluation of Transformative Innovation Policy. TIPC Working Paper, TIPCWP2020-01. <http://www.tipcon sortium.net/wp-content/uploads/2020/07/Paper-FORETIP-1.pdf> accessed 22 Jan 2021.

Naber, R., Raven, R., Kouw, M., et al. (2017) 'Scaling up Sustainable Energy Innovations', Energy Policy, 110: 342-54.

Pekkarinen, S. and Melkas, H. (2019) 'Welfare State Transition in the Making: Focus on the Niche-regime Interaction in Finnish Elderly Care Services', Technological Forecasting and Social Change, 145: 240-53.

Pellicer-Sifres, V., Belda-Miquel, S., Cuesta-Fernandez, I., et al. (2018) 'Learning, Transformative Action, and Grassroots Innovation: Insights from the Spanish Energy Cooperative Som Energia', Energy Research and Social Science, 42: 100-111.

Pohl, C., Krütli, P., and Stauffacher, M. (2017) 'Ten Reflective Steps for Rendering Research Societally Relevant', GAIA - Ecological Perspectives for Science and Society, 26: 43-51.

Raven, R., Kern, F., Verhees, B., et al. (2016) 'Niche Construction and Empowerment through Socio-political Work. A Meta-analysis of Six Low-carbon Technology Cases', Environmental Innovation and Societal Transitions, 18: 164-80.

Raven, R., Sengers, F., Spaeth, P., et al. (2019) 'Urban Experimentation and Institutional Arrangements', European Planning Studies, 27: 258-81.

Raven, R., Van Den Bosch, S., and Weterings, R. (2010) 'Transitions and Strategic Niche Management: Towards a Competence Kit for Practitioners', International Journal of Technology Management, 51: 57-74.

Raven, R., and Verbong, G. (2007) 'Multi-Regime Interactions in the Dutch Energy Sector: the Case of Combined Heat and Power Technologies in the Netherlands 1970-2000', Technology Analysis of Strategic Management, 19: 491-507.

Raven, R., Schot, J., and Berkhout, F. (2012) 'Space and Scale in Socio-Technical Transitions', Environmental Innovation and Societal Transitions, 4: 63-78.

Rip, A. and Kemp, R. (1998) 'Technological Change', in Rayner S. and Malone E. L. (eds) Human Choice and Climate Change: Resources and Technology, pp. 327-99. Columbus, OH: Batelle Press.

Rogge, K. S. and Johnstone, P. (2017) 'Exploring the Role of Phaseout Policies for Low-carbon Energy Transitions: The Case of the German Energiewende', Energy Research and Social Science, 33: 128-37.

Safarzyńska, K. and van den Bergh, J. C. J. M. (2013) 'An Evolutionary Model of Energy Transitions with Interactive Innovation-selection Dynamics', Journal of Evolutionary Economics, 23: 271-93.

Scholz, G. and Methner, N. (2020) 'A Social Learning and Transition Perspective on A Climate Change Project in South Africa', Environmental Innovation and Societal Transitions, 34: 322-35.

Schot, J. and Geels, F. W. (2007) 'Niches in Evolutionary Theories of Technical Change: A Critical Survey of the Literature', Journal of Evolutionary Economics, 17: 605-22.

- (2008) 'Strategic Niche Management and Sustainable Innovation Journeys: Theory, Findings, Research Agenda, and Policy', Technology Analysis and Strategic Management, 20: 537-54.

Schot, J., Kivimaa, P., and Torrens, J. (2019) 'Transforming Experimentation: Experimental Policy Engagements and Their Transformative Outcomes'. <https://www.tipconsortium.net/resource/transformin g-experimentation-experimental-policy-engagements-and-their-tran sformative-outcomes/> accessed 15 Sept 2020.

Schot, J. and Steinmueller, W. E. (2018) 'Three Frames for Innovation Policy: R\&D, Systems of Innovation and Transformative Change', Research Policy, 47: 1554-67.

- (2019) 'Transformative Change: What Role for Science, Technology and Innovation Policy? An Introduction to the 50th Anniver sary of the Science Policy Research Unit (SPRU) Special Issue', Research Policy, 48: 843-8.

Sengers, F., Wieczorek, A. J., and Raven, R. (2019) 'Experimenting for Sustainability Transitions: A Systematic Literature Review', Technological Forecasting and Social Change, 145: 153-64.

Sengers, F., Berkhout, F., Wieczorek, A. J. and Raven, R. (2016) Experimenting in the city: Unpacking notions of experimentation for sustainability. in The experimental city pp. 15-31. Routledge.

Seyfang, G. and Haxeltine, A. (2012) 'Growing Grassroots Innovations: Exploring the Role of Community-Based Initiatives in Governing Sustainable Energy Transitions', Environment and Planning C: Government and Policy, 30: 381-400.

Seyfang, G., Hielscher, S., Hargreaves, T., et al. (2014) 'A Grassroots Sustainable Energy Niche? Reflections on Community Energy in the UK', Environmental Innovation and Societal Transitions, 13: 21-44.

Slingerland, M. and Schut, M. (2014) 'Jatropha Developments in Mozambique: Analysis of Structural Conditions Influencing NicheRegime Interactions', Sustainability, 6: 7541-63.

Smith, A., Kern, F., Raven, R., et al. (2014) 'Spaces for Sustainable Innovation: Solar Photovoltaic Electricity in the UK', Technological Forecasting and Social Change, 81: 115-30.

Smith, A. and Raven, R. (2012) 'What Is Protective Space? Reconsidering Niches in Transitions to Sustainability', Research Policy, 41: 1025-36.

Smith, A., Stirling, A., and Berkhout, F. (2005) 'The Governance of Sustainable Socio-technical Transitions', Research Policy, 34: 1491-510.

Sol, J., Van Der Wal, M. M., Beers, P. J., et al. (2017) 'Reframing the Future: The Role of Reflexivity in Governance Networks in Sustainability Transitions Reframing the Future: The Role of Reflexivity in Governance Networks in Sustainability Transitions', Environmental Education Research, 24: 1383-405.

Sol, J., Van Der Wal, M. M., Beers, P. J., and Wals, A. E. (2018) 'Reframing the Future: the Role of Reflexivity in Governance Networks in Sustainability Transitions', Environmental Education Research, 24: 1383-405.

Sovacool, B. K., Hook, A., Martiskainen, M., et al. (2020a) 'The Decarbonisation Divide: Contextualizing Landscapes of Low-carbon Exploitation and Toxicity in Africa', Global Environmental Change, 60: 102028.

Sovacool, B. K., Turnheim, B., Martiskainen, M., et al. (2020b) 'Guides or Gatekeepers? Incumbent-Oriented Transition Intermediaries in a Low-carbon Era', Energy Research and Social Science, 66: 101490.

Steward, F. (2012) 'Transformative Innovation Policy to Meet the Challenge of Climate Change: Sociotechnical Networks Aligned with Consumption and End-Use as New Transition Arenas for a Low-carbon Society or Green Economy', Technology Analysis and Strategic Management, 24: 331-43.

Streeck, W. and Thelen, K. (2005) Beyond Continuity: Institutional Change in Advanced Political Economies. Oxford: Oxford University Press.

Sutherland, L.-A., Peter, S., and Zagata, L. (2015) 'Conceptualising Multi-regime Interactions: The Role of the Agriculture Sector in Renewable Energy Transitions', Research Policy, 44: 1543-54.

Swilling, M. (2019) The Age of Sustainability: Just Transitions in a Complex World. Oxfordshire: Routledge.

Sydow, J., Schreyögg, G., and Koch, J. (2009) 'Organizational Path Dependence: Opening the Black Box', Academy of Management Review, 34: 689-709.

Torrens, J., Johnstone, P., and Schot, J. (2018) 'Unpacking the Formation of Favourable Environments for Urban Experimentation: The Case of the Bristol Energy Scene', Sustainability, 10: 879. 
Torrens, J., Schot, J., Raven, R., and Johnstone, P. (2019) 'Seedbeds, Harbours, and Battlegrounds: On the Origins of Favourable Environments for Urban Experimentation with sustainability', Environmental Innovation and Societal Transitions, 31: 211-32.

Truffer, B., Voß, J. P., and Konrad, K. (2008) 'Mapping Expectations for System Transformations. Lessons from Sustainability Foresight in German Utility Sectors', Technological Forecasting and Social Change, 75: 1360-72.

Turnheim, B. and Geels, F. W. (2012) 'Regime Destabilisation as the Flipside of Energy Transitions: Lessons from the History of the British Coal Industry (1913-1997)', Energy Policy, 50: 35-49.

Turnheim, B., Kivimaa, P., and Berkhout, F. (2018) Innovating Climate Governance: Moving Beyond Experiments. Cambridge: Cambridge University Press.

van de Kerkhof, M. and Wieczorek, A. (2005) 'Learning and Stakeholder Participation in Transition Processes towards Sustainability: Methodological Considerations', Technological Forecasting and Social Change, 72: 733-47.

van Doren, D., Runhaar, H., Raven, R. P., et al. (2020) 'Institutional Work in Diverse Niche Contexts: The Case of Low-carbon Housing in the Netherlands', Environmental Innovation and Societal Transitions, 35: 116-34.

van Driel, H. and Schot, J. (2005) 'Radical Innovation as a Multilevel Process: Introducing Floating Grain Elevators in the Port of Rotterdam', Technology and Culture, 46: 51-76.

van Lente, H. (2012) 'Navigating Foresight in a Sea of Expectations: Lessons from the Sociology of Expectations', Technology Analysis and Strategic Management, 24: 769-82.

van Mierlo, B., Halbe, J., Beers, P. J., et al. (2020) 'Learning about Learning in Sustainability Transitions', Environmental Innovation and Societal Transitions, 34: 255-69.

van Poeck, K., Östman, L., and Block, T. (2020) 'Opening up the Black Box of Learning-by-doing in Sustainability Transitions', Environmental Innovation and Societal Transitions, 34: 298-310.

van Waes, A., Farla, J., and Raven, R. (2020) 'Why Do Companies' Institutional Strategies Differ across Cities? A Cross-case Analysis of Bike Sharing in Shanghai \& Amsterdam', Environmental Innovation and Societal Transitions, 36: 151-63.
Verbong, G., Geels, F. W., and Raven, R. (2008) 'Multi-niche Analysis of Dynamics and Policies in Dutch Renewable Energy Innovation Journeys (1970-2006): Hype-cycles, Closed Networks and Technology-focused Learning', Technology Analysis and Strategic Management, 20: 555-73.

Verbong, G. P. J. and Geels, F. W. (2010) 'Exploring Sustainability Transitions in the Electricity Sector with Socio-technical Pathways', Technological Forecasting and Social Change, 77: 1214-21.

Vinke-de Kruijf, J., Pahl-Wostl, C., and Knieper, C. (2020) 'Wider Learning Outcomes of European Climate Change Adaptation Projects: A Qualitative Comparative Analysis', Environmental Innovation and Societal Transitions, 34: 270-97.

Voorberg, W. H., Bekkers, V. J., and Tummers, L. G. (2015) 'A Systematic Review of Co-Creation and Co-production: Embarking on the Social Innovation Journey', Public management review, 17: 1333-57.

Voss, J. P., Bauknecht, D. and Kemp, R., eds (2006) Reflexive Governance for Sustainable Development. Cheltenham: Edward Elgar Publishing.

Wagner, A. and Gałuszka, D. (2020) 'Let's Play the Future: Sociotechnical Imaginaries, and Energy Transitions in Serious Digital Games', Energy Research and Social Science, 70: 101674.

Weber, K. M. and Rohracher, H. (2012) 'Legitimizing Research, Technology and Innovation Policies for Transformative Change: Combining Insights from Innovation Systems and Multi-level Perspective in a Comprehensive "failures" Framework', Research Policy, 41: 1037-47.

Wenger, E. (1998) Communities of Practice: Learning, Meaning, and Identity (Learning in Doing: Social, Cognitive and Computational Perspectives). Cambridge: Cambridge University Press.

Wieczorek, A. J., Raven, R., and Berkhout, F. (2015) 'Transnational Linkages in Sustainability Experiments: A Typology and the Case of Solar Photovoltaic Energy in India', Environmental Innovation and Societal Transitions, 17: 149-65.

Yang, K., Hiteva, R. P., and Schot, J. (2020) 'Expectation dynamics and niche acceleration in China's wind and solar power development' Environmental Innovation and Societal Transitions, 36: 177-96. 